Original article

\title{
Prevalence of mental disorders and associated disability: Results from the cross-sectional CZEch mental health Study (CZEMS)
}

\author{
T. Formánek ${ }^{\mathrm{a}}$, A. Kagströmª , P. Cermakova ${ }^{\mathrm{a}, \mathrm{b}}$, L. Csémy ${ }^{\mathrm{a}}$, K. Mladáa ${ }^{\mathrm{a}}$ P. Winkler ${ }^{\mathrm{a}, \mathrm{c}, *}$ \\ a National Institute of Mental Health, Klecany, Czech Republic \\ b Third Faculty of Medicine, Charles University Prague, Czech Republic \\ ${ }^{\mathrm{c}}$ Health Service and Population Research Department, Institute of Psychiatry, Psychology and Neurosciences, King's College London, United Kingdom
}

\section{A R T I C L E IN F O}

\section{Article history:}

Received 13 February 2019

Received in revised form 3 May 2019

Accepted 5 May 2019

Available online 13 May 2019

\section{Keywords:}

Mental disorders

Epidemiology

Disability

Central and Eastern Europe

\begin{abstract}
A B S T R A C T
Introduction: We aimed to estimate the prevalence of current mental disorders in the Czech population, and to identify associated disability.

Methods: We conducted a representative cross-sectional household survey of the Czech adult, community-dwelling population. We used the Mini International Neuropsychiatric Interview (M.I.N. I.), WHO Disability Assessment Schedule (WHODAS) 2.0, and Self-Identification as Mentally Ill (SELFI) scale alongside sociodemographic and other covariates. We reached $75 \%$ response rate. Descriptive statistics of the sample were assessed and median (M) disability levels with interquartile range (IQR) according diagnosis were calculated on a scale ranging from 12 to 50 . Linear regression models were used to identify factors associated with disability.

Results: In our sample of 3306 participants, 21.9\% experienced a mental disorder in 2017. Prevalence rates for mood, anxiety, alcohol use, non-alcohol substance use, and psychotic disorders corresponded to $5.5 \%, 7.3 \%$, $10.8 \%, 2.9 \%$, and $1.5 \%$ respectively. Alcohol dependence was identified in $6.6 \%$, and major depression in $4.0 \%$ of the sample. Disability in the general population was significantly lower $(M=12 ; \mathrm{IQR}=12,17)$ than in those with $\operatorname{mood}(M=20 ; I Q R=14 ; 29)$, anxiety $(M=18 ; I Q R=13 ; 26)$, alcohol use $(M=14 ; I Q R=12 ; 18)$, nonalcohol substance use $(M=15 ; I Q R=12 ; 19)$, or psychotic disorders $(M=22 ; I Q R=16.4 ; 29.4)$.

Conclusions: People with mental disorders have considerably elevated disability in comparison to mentally healthy participants. The prevalence of mental disorders in the Czech Republic is mostly in line with European prevalence rates but it is lower for anxiety disorders and two times higher for alcohol use disorders.
\end{abstract}

(C) 2019 Elsevier Masson SAS. All rights reserved.

\section{Background}

Mental disorders are amongst the top causes of disability in terms of Disability Adjusted Life Years (DALYs) globally [1,2] and depression is now the leading cause of disability [3]. Approximately $25 \%$ of people experience a mental disorder every year $[4,5]$, but the majority of people affected do not receive help due to an array of factors, including stigmatization of mental illness and a lack of access to adequate services [6,7]. World Mental Health Surveys conducted under the umbrella of the World Health Organization (WHO) demonstrated an association between severity of mental disorders and help-seeking behaviour [8],

\footnotetext{
* Corresponding author at: National Institute of Mental Health, Topolova 748, 250 67 Klecany, Czech Republic.

E-mail address: petr.winkler@nudz.cz (P. Winkler).
}

and disability has been considered equally important as mortality for public health [9].

The prevalence of mental disorders and associated disability differs substantially across the globe [10]. Central and eastern Europe (CEE) has the highest rates of alcohol consumption in the world [11], and the region has comparatively high rates of both, suicides [12] and DALYs associated with mental disorders [10]. However, evidence on prevalence of mental disorders, associated disability and treatment gap in CEE is scarce [10,13].

Although there are rights-based, clinical and economic arguments in favour of deinstitutionalization, mental health care systems in the CEE region are mostly institutional and reforms initiated following the collapse of communism remain mostly in the realms of rhetoric [13-15]. Some CEE countries, including the Czech Republic, have recently launched national mental health care reforms [16]. However, a lack of evidence is a major obstacle in pursuing evidence-based mental health care development in the region. Therefore, we aimed to estimate the prevalence of current 
mental disorders and associated disability in the adult communitydwelling Czech population.

\section{Method}

\subsection{Source of data}

In the present study, we analysed data from the CZEch Mental health Study (CZEMS). The CZEMS was designed as a crosssectional national epidemiological survey of mental disorders in the Czech Republic and its methodology is described in detail elsewhere [17]. Briefly, two-staged sampling was used, where a random sample of participants was selected from a random group of voting districts in order to arrive at a representative sample of adults (aged 18 or more years, with no upper limit for age) for the Czech general population in terms of age, gender, education and region. Data was collected by trained interviewers in autumn 2017, using the paper and pencil interviewing (PAPI) method at households of eligible participants. The response rate was $75 \%$ and a total 3306 adults participated in the study. Socio-demographic characteristics of non-responders are not available. All participants were informed of the purpose of the study, provided their informed consent, and all data were anonymized. The study was approved by the Ethics Committee of the National Institute of Mental Health, Czech Republic (registration number 97/18).

\subsection{Assessment of current mental disorders}

The prevalence of mental disorders was assessed using the fifth version of the Mini International Neuropsychiatric Interview (M.I. N.I.) [18]. Individuals were identified as having a mental disorder when their past or current symptomatology met the criteria of the Diagnostic and Statistical Manual IV (DSM-IV) for a given mental disorder. Only current mental disorders are presented in this study. The time frames for considering a mental disorder as current according the M.I.N.I. are: (1) the past two weeks for major depressive episode; (2) the past month for panic, obsessivecompulsive and posttraumatic stress disorder and social phobia and suicidality; (3) the past six months for generalized anxiety disorder, (4) the past twelve months for alcohol and non-alcohol substance dependence and alcohol and non-alcohol substance abuse and (5) the past two years for dysthymia. For manic, hypomanic and psychotic disorders and for agoraphobia, no specific time frames are given in the M.I.N.I to be considered as current.

Participants could fulfil the criteria for the following diagnostic groups: (1) mood disorders (major depressive episode, dysthymia, manic episode and hypomanic episode); (2) anxiety disorders (panic disorder, agoraphobia, social phobia, obsessive-compulsive disorder, posttraumatic stress disorder and generalized anxiety disorder); (3) alcohol use disorders (alcohol dependence and alcohol abuse); (4) non-alcohol substance use disorders (nonalcohol substance dependence and non-alcohol substance abuse; including stimulants, opioids, hallucinogens, inhalants, cannabis, tranquilizers, and others) and (5) psychotic disorders.

\subsection{Disability}

The level of disability was examined using a Czech translation of the 12-item version of WHO Disability Assessment Schedule 2.0 (WHODAS 2.0) [9]. WHODAS 2.0 requires participants to think about their health-related difficulties in performing different activities. Possible answers range from "none" to "extreme or cannot do", covering the following 12 activities: (1) standing for long periods; (2) taking care of household responsibilities; (3) learning a new task; (4) joining in community activities;
(5) being emotionally affected by health problems; (6) concentrating on doing something for $10 \mathrm{~min}$; (7) walking a long distance; (8) washing whole body; (9) getting dressed; (10) dealing with strangers; (11) maintaining a friendship and (12) day-to-day work or school.

Participants may also indicate that a given activity is not applicable to them, in which case it is explored whether it is due to non-health related conditions, and their answer is coded, according to WHODAS 2.0 manual, as "not applicable", otherwise as "extreme or cannot do" [9]. In the present study, we retrospectively assessed whether an item was not applicable due to health or non-health related conditions based on participants' answers to other questions in the questionnaire (see the Supplementary material for details).

In line with the methodology recommended in the WHODAS 2.0 manual, we performed data imputation for participants who had only one missing value using the mean from the other 11 items. Participants with more than one missing value were excluded from all analysis involving WHODAS 2.0. Imputed values were rounded to zero decimal places. We estimated the composite WHODAS 2.0 score following a complex scoring method proposed in the WHODAS 2.0 manual, which resulted in values ranging from 0 (indicating no disability) to 38 (indicating extreme disability). Finally, after performing the complex scoring, we log transformed it in order to enable linear regression modeling since the WHODAS 2.0 score is by nature heavily right skewed. To avoid values of zero where logarithm cannot be meaningfully applied, a +1 constant was added to all responses. Thus, the scores on WHODAS 2.0 before log-transformation could range from 12 to 50. Disability levels were computed based on this WHODAS 2.0 variable, while the regression models used a log-transformation of this.

\subsection{Covariates}

In addition to collecting sociodemographic information, such as age, gender, educational level and marital status, we used the SelfIdentification as Mentally Ill (SELFI) scale to assess whether participants considered themselves as possibly having a mental disorder [19]. SELFI consists of the following five statements which are rated on a Likert-style scale spanning from 1 (dont agree at all) to 5 (agree completely): (1) current issues I am facing could be a sign of a mental illness; (2) the thought of myself as having a mental illness seems doubtful to me; (3) I could be a person that is likely to have a mental illness; (4) I see myself as a person that is mentally healthy and emotionally stable; (5) I am mentally stable, I do not have a mental health problem. The composite SELFI score was calculated by reverse coding items 2,4 and 5, and summing all items together resulting in a score ranging from 5 to 25 , with higher scores indicating decreasing willingness to self-identify as a person that could have a mental disorder.

Participants meeting the criteria for a current psychiatric diagnosis according to M.I.N.I. were examined for mental health related help-seeking behaviour in the past 12 months. Those who reported not seeking and/or not visiting a psychiatrist, psychologist or general practitioner due to mental health problems were considered as not receiving treatment. We analysed differences between those with a diagnosis who have not receive treatment and those with a diagnosis who have received treatment.

Participants were also assessed for both mental and physical comorbidities. We considered participants as having a psychiatric comorbidity when they met the criteria for diagnosis of a mental disorder in at least two diagnostic groups. Participants who fulfilled the criteria for a psychiatric diagnosis were considered as having a somatic comorbidity if they have been either, hospitalized for any somatic illness, treated for a chronic somatic illness or diagnosed with a somatic illness that required regular check-ups 
during the past 12 months. Furthermore, the subjective rating of a participant's own physical condition was assessed through one question, with answers ranging from "very good" to "very bad" on a 5-point Likert-like scale. Finally, patterns of pharmaceutical consumption were examined through multiple questions. Participants were asked to indicate whether they had been using pain killers, sleeping pills, tranquilizers, or stimulants, and if so, how often. Participants who used at least one group of pharmaceuticals once or more times per week were compared with other participants.

\subsection{Statistical analysis}

We used descriptive statistics to assess socio-demographic characteristics of the sample. We calculated prevalence rates of mental disorders for distinctive diagnostic groups, as well as for every single diagnosis examined in this study. For the prevalence rates, we calculated a $95 \%$ confidence interval $(95 \% \mathrm{CI})$ using the bootstrap method with 10000 bootstrap replicates. We also calculated the female to male ratio for given diagnosis. Based on M. I.N.I. responses we calculated the median (M) disability levels with interquartile range (IQR), presented as a range between $25^{\text {th }}$ and $75^{\text {th }}$ percentile, for the sample of respondents with, no diagnosis, with any psychiatric diagnosis, and within each of the specific diagnostic groups. To deal with the slightly higher proportion (approximately $2 \%$ ) of women in the sample, post-stratification weights were employed.

We constructed multiple linear regression models for the following groups of participants according to their psychiatric diagnosis: any psychiatric diagnosis, mood disorders, anxiety disorders, alcohol use disorders, non-alcohol substance use disorders and psychotic disorders. The log-transformed composite WHODAS 2.0 score was employed as the dependent variable. All models used the same set of predictors which included the SELFI score, self-rated physical condition, psychiatric comorbidity, somatic comorbidity, consumption of at least one group of pharmaceuticals once or more times per week, and not receiving treatment for mental health condition. The descriptive statistics of covariates based on psychiatric diagnosis are provided in Supplementary material. All models were adjusted for age, gender, educational level and marital status. Only participants with complete data on all variables were included in analysis $(n=3$ 268). Post-stratification weights were used to control for the slightly higher proportion of women in the sample. Associations with $\mathrm{p}<0.05$ were considered as statistically significant. The results of linear regression models were expressed as nonstandardized beta coefficients (B) with $95 \% \mathrm{CI}$. The quality of model fits was assessed via the adjusted coefficients of determination $\left(\mathrm{R}^{2}\right)$. Analysis was conducted in $\mathrm{R}$ statistical programming language (version 3.4.4).

\section{Results}

\subsection{Socio-demographic characteristics of participants'}

Our sample included 3306 individuals (mean age 49 years, 54\% female) representative of the Czech adult community-dwelling population in terms of gender, age, and education. Approximately $9 \%$ of participants finished primary school, $39 \%$ achieved vocational education, $36 \%$ high school and $17 \%$ higher education. More than $60 \%$ of participants were married or cohabiting, and approximately the same proportion were employed. Detailed characteristics of the sample have been previously published [17].

\subsection{Prevalence of mental disorders}

Detailed estimates of current prevalence of mental disorders are reported in Table 1 . More than $21 \%$ of participants fulfilled the criteria for having at least one current mental disorder. More than $10 \%$ of participants were screened positive for alcohol use disorders, including $6.6 \%$ of participants with alcohol dependence. About $7.3 \%$ of people were screened positive for anxiety disorders and $5.5 \%$ for mood disorders, including $4 \%$ with major depressive episodes. Furthermore, $1.5 \%$ of participants scored positive for a current psychotic disorder. We identified considerable differences between females and males. While females met the criteria for mood, anxiety and psychotic disorders two to three times more often, they met the criteria for alcohol use disorders and non-alcohol substance use disorders 0.4 to 0.6 times less often than males.

Table 1

Prevalence of mental disorders in the nationally representative sample of community-dwelling Czech adults (aged 18+).

\begin{tabular}{|c|c|c|}
\hline Diagnosis (DSM-IV) & $\%(95 \% \mathrm{CI})$ & $\begin{array}{l}\text { Gender ratio } \\
\text { f:m }\end{array}$ \\
\hline Any current mental disorder & $21.86(20.42 ; 23.29)$ & 0.98 \\
\hline Mood disorders & $5.52(4.74 ; 6.3)$ & 2.33 \\
\hline Anxiety disorders & $7.27(6.38 ; 8.15)$ & 2.75 \\
\hline Alcohol use disorders & $10.84(9.76 ; 11.92)$ & 0.36 \\
\hline Non-alcohol substance use disorders & $2.94(2.35 ; 3.53)$ & 0.62 \\
\hline Psychotic disorders & $1.45(1.05 ; 1.86)$ & 3.36 \\
\hline \multicolumn{3}{|l|}{ Mood disorders } \\
\hline Major depression episode & $3.96(3.29 ; 4.62)$ & 3.55 \\
\hline Dysthymia & $1(0.66 ; 1.35)$ & 2.3 \\
\hline Manic episode & $0.76(0.46 ; 1.06)$ & 1.27 \\
\hline Hypomanic episode & $1.31(0.92 ; 1.7)$ & 1.05 \\
\hline \multicolumn{3}{|l|}{ Anxiety disorders } \\
\hline Panic disorder & $0.21(0.05 ; 0.37)$ & 2.5 \\
\hline Agoraphobia & $5.16(4.41 ; 5.91)$ & 2.58 \\
\hline Social phobia & $1.67(1.24 ; 2.11)$ & 4.18 \\
\hline Generalized anxiety disorder & $0.64(0.37 ; 0.91)$ & 4.5 \\
\hline Obsessive-compulsive disorder & $0.99(0.65 ; 1.33)$ & 1.75 \\
\hline Post-traumatic stress disorder & $0.96(0.63 ; 1.3)$ & 5.4 \\
\hline \multicolumn{3}{|c|}{ Alcohol and non-alcohol substance use disorders } \\
\hline Alcohol dependence & $6.61(5.75 ; 7.47)$ & 0.31 \\
\hline Alcohol abuse & $9.42(8.41 ; 10.44)$ & 0.31 \\
\hline Non-alcohol substance dependence & $2.19(1.67 ; 2.71)$ & 0.6 \\
\hline Non-alcohol substance abuse & $2.24(1.72 ; 2.75)$ & 0.48 \\
\hline
\end{tabular}


Table 2

Disability levels for the whole sample and for participants in specific diagnostic groups.

\begin{tabular}{lll}
\hline Group & Median & Interquartile range \\
\hline Whole sample $(\mathrm{n}=3$ 268) & 12 & $12 ; 17$ \\
No current mental disorder $(\mathrm{n}=2559)$ & 12 & $12 ; 16$ \\
Any current mental disorder $(\mathrm{n}=709)$ & 15 & $12 ; 22$ \\
Mood disorders $(\mathrm{n}=181)$ & 20 & $14 ; 29$ \\
Anxiety disorders $(\mathrm{n}=241)$ & 18 & $13 ; 26$ \\
Alcohol use disorders $(\mathrm{n}=344)$ & 14 & $12 ; 18$ \\
Non-alcohol substance use disorders $(\mathrm{n}=94)$ & 15 & $12 ; 19$ \\
Psychotic disorders $(\mathrm{n}=48)$ & 22 & $16.4 ; 29.4$ \\
\hline
\end{tabular}

\subsection{Disability}

Disability levels are shown in Table 2 . The median disability level for the entire sample was $12(\mathrm{IQR}=12 ; 17)$. The median disability level for participants with no mental disorder was $12(\mathrm{IQR}=12 ; 16)$, compared to a median disability of $15(\mathrm{IQR}=12 ; 22)$ for those with mental disorder. Within specific diagnostic groups, the highest level of disability was found in participants with psychotic disorders $(\mathrm{M}=22 ; \mathrm{IQR}=16.4 ; 29.4)$ and the lowest in the group of participants with alcohol use disorders $(\mathrm{M}=14 ; \mathrm{IQR}=12 ; 18)$.

\subsection{Associations between respondents characteristics and disability}

Detailed results of the multiple linear regression models are shown in Table 3. Negative subjective rating of physical condition $(\mathrm{B}=0.12 ; 95 \% \mathrm{CI}=0.09 ; 0.14)$, having a somatic comorbidity $(B=0.06 ; 95 \% C I=0.02 ; 0.11)$, and consuming at least one group of pharmaceuticals once or more times per week $(B=0.10 ; 95 \%$ $\mathrm{CI}=0.05 ; 0.14$ ) were found to be associated with increased levels of disability among participants with any mental disorder. On the other hand, higher SELFI scores were found to be associated with lower disability $(\mathrm{B}=-0.01 ; 95 \% \mathrm{CI}=-0.02 ;-0.01)$ indicating that people with a high level of disability are more likely to consider themselves as persons with mental disorders.
For participants with mood disorders, only subjective ratings of physical conditions were found to be associated with disability as measured by WHODAS $2.0(\mathrm{~B}=0.14 ; 95 \% \mathrm{CI}=0.09 ; 0.19)$ and participants with more negative ratings demonstrated higher levels of disability. In individuals with anxiety disorders, the subjective rating of physical condition $(B=0.16,95 \% C I=0.12 ; 0.21)$, having a psychiatric comorbidity $(B=0.09,95 \% C I=0.02 ; 0.17)$ and consumption of at least one group of pharmaceuticals once or more times per week $(B=0.10,95 \% C I=0.03 ; 0.18)$, were found to be associated with higher levels of disability. On the other hand, participants who were not treated for their mental health condition, were found to have a lower level of disability ( $\mathrm{B}=$ $-0.10,95 \% \mathrm{CI}=-0.19 ;-0.01)$ as compared to those who received treatment. Moreover, higher SELFI scores were found to be associated with lower disability $(\mathrm{B}=-0.01,95 \% \mathrm{CI}=-0.02 ;-0.00)$.

In participants with alcohol use disorders, worse subjective rating of physical condition $(B=0.05,95 \% \mathrm{CI}=0.01 ; 0.08)$, psychiatric comorbidity $(B=0.09,95 \% C I=0.03 ; 0.15)$, somatic comorbidity $(\mathrm{B}=0.09,95 \% \mathrm{CI}=0.02 ; 0.15)$, and consumption of at least one group of pharmaceuticals once or more times per week $(B=0.12,95 \%$ $\mathrm{CI}=0.04 ; 0.19$ ), were all found to be associated with higher levels of disability. Also, higher scores on SELFI $(B=-0.01,95 \% C I=-0.02 ;-0.00)$ and not receiving treatment for mental health condition $(B=-0.17$, $95 \% \mathrm{CI}=-0.29 ;-0.05)$, were associated with lower disability. For participants with non-alcohol substance use disorders, worse selfrated physical condition $(B=0.07 ; 95 \% C I=0.00 ; 0.13$ ) was found to be associated with higher level of disability.

In individuals with psychotic disorders, negative subjective ratings of physical condition $(\mathrm{B}=0.11 ; 95 \% \mathrm{CI}=0.01 ; 0.20)$ and having a somatic comorbidity $(B=0.19 ; 95 \% C I=0.02 ; 0.35)$ were associated with higher disability. All regression models displayed a meaningfully strong explanatory power, with the adjusted $\mathrm{R}^{2}$ coefficients ranging from 0.34 to 0.66 .

\section{Discussion}

This study demonstrates that over one fifth of the Czech adult population experienced a mental disorder in 2017, and those

Table 3

Associations of respondents' characteristics with disability, according to diagnostic groups.

\begin{tabular}{|c|c|c|c|c|c|c|}
\hline & $\begin{array}{l}\text { Any } \\
\text { mental disorder }\end{array}$ & Mood disorders & Anxiety disorders & $\begin{array}{l}\text { Alcohol use } \\
\text { disorders }\end{array}$ & $\begin{array}{l}\text { Non-alcohol substance } \\
\text { use disorders }\end{array}$ & Psychotic disorders \\
\hline SELFI & $\begin{array}{l}-0.01^{* * *}(95 \% \mathrm{CI}= \\
-0.02 ;-0.01)\end{array}$ & $\begin{array}{l}-0.01(95 \% \mathrm{CI}= \\
-0.03 ; 0.00)\end{array}$ & $\begin{array}{l}-0.01^{*}(95 \% \mathrm{CI}= \\
-0.02 ;-0.00)\end{array}$ & $\begin{array}{l}-0.01^{* *}(95 \% \mathrm{CI}= \\
-0.02 ;-0.00)\end{array}$ & $\begin{array}{l}-0.01(95 \% \mathrm{CI}=-0.03 \\
0.00)\end{array}$ & $\begin{array}{l}-0.01(95 \% \mathrm{CI}= \\
-0.03 ; 0.01)\end{array}$ \\
\hline Rating of physical condition & $\begin{array}{l}0.12^{* * * *}(95 \% \\
\mathrm{CI}=0.09 ; 0.14)\end{array}$ & $\begin{array}{l}0.14^{* * *}(95 \% \\
\mathrm{CI}=0.09 ; 0.19)\end{array}$ & $\begin{array}{l}0.16^{* * * *}(95 \% \\
C I=0.12 ; 0.21)\end{array}$ & $\begin{array}{l}0.05^{* *}(95 \% \\
\mathrm{CI}=0.01 ; 0.08)\end{array}$ & $\begin{array}{l}0.07^{*}(95 \% \mathrm{CI}=0.00 \\
0.13)\end{array}$ & $0.11^{*}(0.01 ; 0.20)$ \\
\hline \multicolumn{7}{|l|}{ Any current psychiatric comorbidity } \\
\hline No & Ref. & Ref. & Ref. & Ref. & Ref. & Ref. \\
\hline Yes & $\begin{array}{l}0.04(95 \% \mathrm{CI}= \\
-0.00,0.07)\end{array}$ & $\begin{array}{l}0.05(95 \% \mathrm{CI}= \\
-0.04 ; 0.14)\end{array}$ & $\begin{array}{l}0.09^{*}(95 \% \\
C I=0.02 ; 0.17)\end{array}$ & $\begin{array}{l}0.09^{* *}(95 \% \\
\mathrm{CI}=0.03 ; 0.15)\end{array}$ & $\begin{array}{l}0.10(95 \% \mathrm{CI}=-0.04 \\
0.23)\end{array}$ & $\begin{array}{l}0.06(95 \% \mathrm{CI}= \\
-0.09 ; 0.22)\end{array}$ \\
\hline \multicolumn{7}{|l|}{ Any current somatic comorbidity } \\
\hline No & Ref. & Ref. & Ref. & Ref. & Ref. & Ref. \\
\hline Yes & $\begin{array}{l}0.06^{* *}(95 \% \\
\mathrm{CI}=0.02 ; 0.11)\end{array}$ & $\begin{array}{l}0.08(95 \% \mathrm{CI}= \\
-0.02 ; 0.18)\end{array}$ & $\begin{array}{l}0.01(95 \% \mathrm{CI}= \\
-0.06 ; 0.09)\end{array}$ & $\begin{array}{l}0.09^{* *}(95 \% \\
\mathrm{CI}=0.02 ; 0.15)\end{array}$ & $\begin{array}{l}0.04(95 \% \mathrm{CI}=-0.09 \\
0.17)\end{array}$ & $\begin{array}{l}0.19^{*}(95 \% \\
\mathrm{CI}=0.02 ; 0.35)\end{array}$ \\
\hline \multicolumn{7}{|l|}{ Pharmaceuticals consumption } \\
\hline Other & Ref. & Ref. & Ref. & Ref. & Ref. & Ref. \\
\hline $\begin{array}{l}\text { At least one group of pharmaceuticals at } \\
\text { least 1-4 times per week }\end{array}$ & $\begin{array}{l}0.10^{* * * *}(95 \% \\
\mathrm{CI}=0.05,0.14)\end{array}$ & $\begin{array}{l}0.03(95 \% \mathrm{CI}= \\
-0.07 ; 0.13)\end{array}$ & $\begin{array}{l}0.10^{* *}(95 \% \\
\mathrm{CI}=0.03 ; 0.18)\end{array}$ & $\begin{array}{l}0.12^{* *}(95 \% \\
\mathrm{CI}=0.04 ; 0.19)\end{array}$ & $\begin{array}{l}0.13(95 \% \mathrm{CI}=-0.01 \text {; } \\
0.27)\end{array}$ & $\begin{array}{l}0.14(95 \% \mathrm{CI}= \\
-0.01 ; 0.29)\end{array}$ \\
\hline \multicolumn{7}{|l|}{ Treatment } \\
\hline Treated & Ref. & Ref. & Ref. & Ref. & Ref. & Ref. \\
\hline Not treated & $\begin{array}{l}-0.06(95 \% \mathrm{CI}= \\
-0.12 ; 0.01)\end{array}$ & $\begin{array}{l}-0.02(95 \% \mathrm{CI}= \\
-0.13 ; 0.09)\end{array}$ & $\begin{array}{l}-0.10^{*}(95 \% \mathrm{CI}= \\
-0.19 ;-0.01)\end{array}$ & $\begin{array}{l}-0.17^{* *}(95 \% \mathrm{CI}= \\
-0.29,-0.05)\end{array}$ & $\begin{array}{l}-0.04(95 \% \mathrm{CI}=-0.26 \\
0.18)\end{array}$ & $\begin{array}{l}-0.20(95 \% \mathrm{CI}= \\
-0.41 ; 0.02)\end{array}$ \\
\hline Observations & 709 & 181 & 241 & 344 & 94 & 48 \\
\hline Adjusted $\mathrm{R}^{2}$ & 0.55 & 0.52 & 0.61 & 0.44 & 0.34 & 0.66 \\
\hline
\end{tabular}

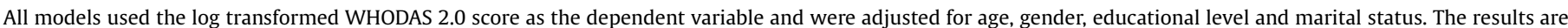
presented as unstandardized beta coefficients with $95 \%$ confidence intervals. "Ref." indicates the reference category in a dummy coded variable.

${ }^{*} \mathrm{p}<.05$.

$\mathrm{p}<.01$.

$\mathrm{p}<.001$. 
identified as having a current mental disorder have a considerably higher disability than the general population. Evidence suggests that prevalence of common mental disorders by world regions differ in magnitude, spanning from $11.5 \%$ in high-income Asian countries to $24.7 \%$ in low- and middle-income Middle East and North Africa [20]. In this study, the prevalence of current mental disorders in the community-dwelling population of the Czech Republic 2017 was found to be slightly lower than the prevalence reported in European review of size and burden of mental disorders in Europe 2011 (21.9\% vs 27.1\%) [5]; though when compared to global regions the Czech population presented more common mental disorders than other countries and the prevalence for common mental disorders found in this study is $2.6 \%$ higher than the estimate for low and middle income Europe and Central Asia $(19.3 \%)$ and $4.8 \%$ higher than for high income European countries (17.1\%) [20]. Considering individual diagnostic groups, the prevalence of psychotic disorders in our study was found to be in line with European estimates (1.2\% in Europe); the prevalence of mood and anxiety disorders were lower in the Czech Republic (5.5\% and 7.4\%) than in Europe in some estimates (7.3\% and 14\%); and the prevalence of alcohol dependence was found to be almost two times higher in the Czech Republic (6.6\% vs. 3.4\%) [5]. However, discrepancies are likely reflecting differences in screening tools, examined time-periods, study designs, DSM criteria for mental disorders and quality of the studies included in the European review. Studies aimed at controlling marked differences between diagnostic tools in order to accurately undertake global comparisons of prevalence are needed.

Discrepancies of prevalence rates for mental disorders between the Czech Republic and other European countries may be due to the high rate of institutionalized persons with mental health disorders, who were not included in this study. This unaccountedfor sub-population in the Czech context is notable as it is comparatively larger than other European contexts [13], especially in comparison to countries outside of the region of CEE where institutionalization is not the primary form of mental health care.

We found considerable disability to be associated with mental disorders. It is in accordance with the results from the European Study of the Epidemiology of Mental Disorders [21], where all of the examined mental disorders were identified with higher work loss days index and lower physical and mental quality of life, as measured by the 12-item WHODAS 2.0 instrument [21]. Similarly, Ormel and colleagues using data based on WHO Mental Health Survey Initiative from 15 countries, have found that in both highincome and low- and middle-income countries, the disability ratings, as measured by Sheehan Disability Scales, were generally higher for mental disorders that for physical disorders [22]. Also, Bruffaerts and colleagues conducted a study based on 26 nationally representative samples and found mental disorders to be associated with a higher number of days with disability than physical disorders [23]. Our results are remarkably similar to the results of 2012 Canadian Community Health Survey (CCHS) which was conducted on nearly 24000 of participants and which used the 12 item WHODAS 2.0, with scores ranging from 12 to 60 , to assess disability in a community dwelling $18+$ years population [24]. The Canadian survey found higher disability to be associated with all mental disorders; least with alcohol use $(M=15.2,95 \%$ $\mathrm{CI}=14.7 ; 15.7)$, and most with psychotic disorders $(\mathrm{M}=23.1,95 \%$ $\mathrm{CI}=19.5$; 26.7) [24].

We suggest that the lower level of disability found in participants with alcohol use disorders in our sample may be partially explained by the inclusion of mild and moderate levels of alcohol use disorders which are associated with less functional disabilities [25,26] (Grant et al., 2015; WHO, 2018). Also, based on statistics published by Organisation for Economic Co-operation and Development (OECD), the alcohol consumption of Czech adults exceeds the European Union (EU) average by about 2 litres (11.9 vs 10 litres) [27] which may suggest a specific drinking culture in Czech Republic where standard definitions for alcohol use disorders are not entirely appropriate.

In the BEAR study, using path models, lower level of functioning was found to be associated with help-seeking, indicating that people seek help for their mental disorders after they begin to affect their occupational and psychosocial functioning [28]. Using linear regression models, we found that receiving treatment was associated with higher disability in the case of anxiety and alcohol use disorders, but not in other diagnostic groups. We hypothesized that this finding could have been caused by the presence of a mediator, so we assessed the treatment gap rigorously in a separate study and we found that higher treatment gap in our sample was associated with being a male, living in rural area, absence of physical comorbidities and also with lower disability, for which, however, the effect size was very small [29].

\subsection{Strengths and limitations}

This study provides nationally representative estimates for the prevalence of current mental disorders for community-dwelling adults in the Czech Republic contributing to the global knowledge on prevalence for mental disorders for the otherwise underresearched region of CEE. This study has several limitations. First, as previously discussed, the results are likely underestimating the true prevalence of mental disorders in the Czech Republic due to not including institutionalized people and the fact that the diagnoses of mental disorders were based on current symptomatology and not on medical history or currently used pharmacotherapy. Second, it has been shown in validation studies of previous epidemiological studies using national samples that schizophrenia and other non-affective psychoses could be seriously overestimated $[8,30,31]$, and it is important to take this into account also in our study. Third, the present study did not include specific phobias, thus the prevalence of anxiety disorders could have been non-trivially underestimated [32]. Forth, there is no available information about the sociodemographic characteristics of non-responders. Therefore, we cannot conclude which groups of people did not participate in this study, which could bias our results in either direction. Finally, the study is based on a clustered sample but we do not have information on cluster membership, therefore we cannot account for the potential bias stemming from this design. On the other hand, although there are some regional differences, Czechia is a small and homogeneous country in regard to health state, thus the potential bias stemming from clustering effects should be rather small.

\section{Conclusions}

This study provides a nationally representative estimate for the prevalence of mental disorders and associated disability in the Czech Republic. We have found a lower overall prevalence of mental disorders in the Czech Republic, when compared to European averages. Within distinctive diagnostic groups, the prevalence of mood and anxiety disorders was found to be lower in Czech Republic than in Europe, while the prevalence of alcohol use disorders was found to be considerably higher in Czech Republic. The prevalence rates of non-alcohol substance use disorders and psychotic disorders are consistent with European observations. All mental disorders were identified with an elevated level of disability. National priorities for mental health care provision should consider specific targeted interventions to prevent and treat alcohol abuse and dependence disorders, as well as the problems associated with high rates of disability in 
people with mental illness and low readiness to self-identify as a person with mental health problems. As reform initiatives of deinstitutionalization of mental health services succeed, the prevalence rates for mental illness in the community can be expected rise as people with mental illness are reintegrated into the community, and it will be important to consider this in planning for community-based services.

Taking into consideration the ongoing reform of psychiatric services in the Czech Republic which focuses largely on deinstitutionalisation (28), identifying and understanding the factors which contribute to the high rates of disability in people with mental illness will be necessary to informing mechanisms and interventions which promote the ability and rights of people with mental illness to participate to their fullest extent within their community.

\section{Declaration of interest}

None.

\section{Author contribution}

TF and PW are the guarantors of the study. TF, PW, PC and KM contributed to the design of the study. TF performed the data analysis. TF, AK and PW created the draft of the manuscript. LC, PC and KM critically commented the draft. TF, AK and PW finalized the manuscript.

\section{Data availability}

The authors have full access to the study data. Access to the data may be given by contacting the correspondence author.

\section{Funding}

The authors were supported by the project "Sustainability for the National Institute of Mental Health" (grant L01611), with financial support from the Ministry of Education, Youth and Sports of the Czech Republic.

\section{Acknowledgments}

None.

\section{Appendix A. Supplementary data}

Supplementary material related to this article can be found, in the online version, at doi:https://doi.org/10.1016/j.eurpsy.2019.05.001.

\section{References}

[1] Murray CJ, Lopez AD, Organization WH. The global burden of disease: a comprehensive assessment of mortality and disability from diseases, injuries, and risk factors in 1990 and projected to 2020: summary. 1996.

[2] Whiteford HA, Ferrari AJ, Degenhardt L, Feigin V, Vos T. The global burden of mental, neurological and substance use disorders: an analysis from the Global Burden of Disease Study 2010. PLoS One 2015;10:e0116820.

[3] WHO. Depression and other common mental disorders: global health estimates. Geneva: WHO; 2017.

[4] Wittchen H-U, Jacobi F. Size and burden of mental disorders in Europe-a critical review and appraisal of 27 studies. Eur Neuropsychopharmacol 2005; $15: 357-76$

[5] Wittchen H-U, Jacobi F, Rehm J, Gustavsson A, Svensson M, Jönsson B, et al. The size and burden of mental disorders and other disorders of the brain in Europe 2010. Eur Neuropsychopharmacol 2011;21:655-79.
[6] The European mental health action plan. Copenhagen: WHO organization regional office to Europe. WHO; 2013.

[7] Nutt DJ. The full cost and burden of disorders of the brain in Europe exposed for the first time. Eur Neuropsychopharmacol 2011;21:715-7.

[8] Demyttenaere K, Bruffaerts R, Posada-Villa J, Gasquet I, Kovess V, Lepine J, et al. Prevalence, severity, and unmet need for treatment of mental disorders in the World Health Organization World Mental Health Surveys. Jama 2004:291:2581-90.

[9] Üstün T, Kostanjsek N, Chatterji S, Rehm J. Manual for WHO disability assessment schedule. 2010.

[10] Whiteford HA, Degenhardt L, Rehm J, Baxter AJ, Ferrari AJ, Erskine HE, et al Global burden of disease attributable to mental and substance use disorders: findings from the Global Burden of Disease Study 2010. Lancet 2013;382:1575-86

[11] Gmel G, Labhart F, Shield KD, Rylett M, Lachenmeier DW, Rehm J. A global overview of alcohol consumpiton patterns. Alcohol: science, policy and public health. Oxford: Oxford University Press; 2013. p. 115-24.

[12] Preventing suicide: a global imperative: world health organization. WHO; 2014.

[13] Winkler P, Krupchanka D, Roberts T, Kondratova L, Machù V, Höschl C, et al. A blind spot on the global mental health map: a scoping review of 25 years' development of mental health care for people with severe mental illnesses in central and eastern Europe. Lancet Psychiatry 2017;4:634-42.

[14] Winkler P, Broulíková HM, Kondrátová L, Knapp M, Arteel P, Boyer P, et al. Value of schizophrenia treatment II: decision modelling for developing early detection and early intervention services in the Czech Republic. Eur Psychiatry 2018;53:116-22.

[15] Winkler P, Koeser L, Kondrátová L, Broulíková HM, Páv M, Kališová L, et al. Costeffectiveness of care for people with psychosis in the community and psychiatric hospitals in the Czech Republic: an economic analysis. Lancet Psychiatry 2018;5(12):1023-31.

[16] Pěč O. Mental health reforms in the Czech Republic. BJ Psych Int 2018:1-3.

[17] Winkler P, Formánek T, Mladá K, Cermakova P. The CZEch Mental health Study (CZEMS): study rationale, design, and methods. Int J Methods Psychiatr Res 2018;27:.

[18] Sheehan DV, Lecrubier Y, Sheehan KH, Amorim P, Janavs J, Weiller E, et al. The Mini-International Neuropsychiatric Interview (M.I.N.I.): the development and validation of a structured diagnostic psychiatric interview for DSM-IV and ICD-10. J Clin Psychiatry 1998;59(Suppl 20)22-33 quiz 4-57.

[19] Schomerus G, Auer C, Rhode D, Luppa M, Freyberger HJ, Schmidt S. Personal stigma, problem appraisal and perceived need for professional help in currently untreated depressed persons. J Affect Disord 2012;139:94-7.

[20] Steel Z, Marnane C, Iranpour C, Chey T, Jackson JW, Patel V, et al. The global prevalence of common mental disorders: a systematic review and metaanalysis 1980-2013. Int J Epidemiol 2014;43:476-93.

[21] Alonso J, Angermeyer MC, Bernert S, Bruffaerts R, Brugha TS, Bryson H, et al. Disability and quality of life impact of mental disorders in Europe: results from the European Study of the Epidemiology of Mental Disorders (ESEMeD) project. Acta Psychiatrica Scand Suppl 2004;109:38-46.

[22] Ormel J, Petukhova M, Chatterji S, Aguilar-Gaxiola S, Alonso J, Angermeyer MC, et al. Disability and treatment of specific mental and physical disorders across the world. Br J Psychiatry 2008;192:368-75.

[23] Bruffaerts R, Vilagut G, Demyttenaere K, Alonso J, AlHamzawi A, Andrade LH, et al. Role of common mental and physical disorders in partial disability around the world. Br J Psychiatry 2012;200:454-61.

[24] Sjonnesen K, Bulloch AG, Williams J, Lavorato D, B. Patten S. Characterization of disability in Canadians with mental disorders using an abbreviated version of a DSM-5 emerging measure: the 12-Item WHO Disability Assessment schedule (WHODAS) 2.0. Can J Psychiatry 2016;61:227-35.

[25] Grant BF, Saha TD, June Ruan W, Goldstein RB, Patricia Chou S, Jung J, et al. Epidemiology of DSM-5 drug use disorder results from the national epidemiologic survey on alcohol and related conditions-III. JAMA Psychiatry 2016;73:39-47.

[26] WHO. Global Status Report on Alcohol and Health 2018. Geneva: WHO; 2018.

[27] OECD. Health at a Glance 2017: OECD Indicators. Paris: OECD Publishing; 2017.

[28] Michel C, Schnyder N, Schmidt SJ, Groth N, Schimmelmann BG, Schultze-Lutter F. Functioning mediates help-seeking for mental problems in the general population. Eur Psychiatry 2018;54:1-9.

[29] Kagstrom A, Alexova A, Tuskova E, Csajbók Z, Schomerus G, Formanek T, Mladá K, Winkler P, Cermakova P. The treatment gap for mental disorders and associated factors in the Czech Republic. Eur Psychiatry 2019;59:37-43.

[30] Eaton WW, Romanoski A, Anthony JC, Nestadt G. Screening for psychosis in the general population with a self-report interview. J Nerv Ment Dis 1991;179:689-93.

[31] Gustavson K, Knudsen AK, Nesvåg R, Knudsen GP, Vollset SE, ReichbornKjennerud T. Prevalence and stability of mental disorders among young adults: findings from a longitudinal study. BMC Psychiatry 2018;18:.

[32] Bebbington P, Nayani T. The psychosis screening questionnaire. Int J Methods Psychiatr Res 1996;5:11-9. 